\title{
The Application of Woven Kenaf in Bio- Composite Production
}

\author{
Muhammad Taufiq Jumadi ${ }^{1 *}$, Muhd Ridzuan Mansor ${ }^{1}$ and Zaleha Mustafa ${ }^{2}$ \\ ${ }^{1}$ Fakulti Kejuruteraan Mekanikal, Universiti Teknikal Malaysia Melaka, Malaysia \\ ${ }^{2}$ Fakulti Kejuruteraan Pembuatan, Universiti Teknikal Malaysia Melaka, Malaysia
}

*Corresponding author: Muhammad Taufiq Jumadi, Fakulti Kejuruteraan Mekanikal, Universiti Teknikal Malaysia Melaka, 76100 Durian Tunggal, Melaka, Malaysia

submission: 監May 26, 2018; Published: 筒 June 08, 2018

\begin{abstract}
The development of natural fibre-based bio composite is taken as the alternative of using synthetic-fibre based composite. This is due to environmental concern and the depletion of non-renewable resource to produce synthetic fibre. Among those natural fibres that available in market, the woven kenaf fibre has received good attention as to be used for bio composite production due to the readability in some regions especially in Malaysia. In this mini review, the authors would like to address the recent studies on the woven kenaf fibre reinforced thermoset bio composite. Apart from that, the commonly used thermoset for bio composite production also been discussed. The outcome from this paper may highlight the applicability of woven kenaf fibre and increase the interest of researchers to develop their product by using woven kenaf fibre.
\end{abstract}

Keywords: Woven kenaf; Thermoset polymer; Bio composite

\section{Introduction}

Textile manufacturing from natural fibre has been used for making the household appliance such as bag, rope, and even cloth. Several functions of hemp fibre have been used by traditional Nepalian as recorded by Robert. This including the hemp fibre is used for rope, grain storage sack (bura), sash belts and Bhangara cloth [1]. Other than that, the yellowish-coarse fabric named as jute is usually applied for manufacturing packing and coarse fabric such as hessian, sacking, carpet, and carpet backing cloth [2]. In addition, the kenaf fibre has potential to be adapted as excellent source for pulp, and paper as well as nursery pots and sheets $[3,4]$.

In the report written by Bengtsson et al. [5], the natural-based textile has the potential to be used for advanced application such as impact protection. This including for ballistic textiles, body armour and fuselage. Textile composites can meet the requirement of tough, high modulus and high strength since they are important for impact protection application. Furthermore, the textile composite with low weight characteristic is an additional factor for production of high-speed naval ships, road vehicles and aircrafts. This also may reduce the manufacturing and operating costs. This mini review will focus on recent findings on the use of woven kenaf fibres for bio composite production. Besides that, this paper also includes the typical thermoset resin that used for bio composite production.

\section{Type of thermoset matrix resin}

The production of bio composite usually done by combining the natural fibre with either thermoplastic or thermoset matrices.

Thermoset is strengthening when heat is applied caused by the cross-linking polymeric chains. The commodity thermoset that commonly used thermoset in natural fibre composite are polyester, epoxy, and vinyl esters [6]. Resin transfer moulding (RTM) is said as the popular thermoset based composite used in producing large and complex part for automotive and aerospace industries [7]. However, Salman et al. [8] reported the technique of producing woven fibre reinforced thermoset composites by using vacuum infusion technique is better than conventional method. This method is said could provide better fibre-to-resin ratio, less wasted resin, very consistent resin usage, and unlimited set-up time, and even cleaner [8].

Polyester: Several researchers have reported the use of polyester as the resin. Al-Kaabi et al. [9] reported the flexural performance of date palm fibre reinforced polyester composite (DPF/Polyester). Based on various fibre lengths, the composite with $2.0 \mathrm{~cm}$ length has better flexural strength as compared to $3.0 \mathrm{~cm}$ length. This is caused by the entanglement of fibre formed in longer fibre. For the case of variation of fibre content, the composite 
with 9 wt.\% of fibre has the optimum flexural strength compared to $10 \mathrm{wt} . \%$ fibre content, due to more fibre to fibre contact and inefficient fibre to matrix bond in higher fibre content composite. The performance of the DPF/Polyester also observed by relating the effect of detergent treated fibre to untreated fibre. Figure 1a showed the untreated fibre which have smoother surface whereas Figure $1 \mathrm{~b}$ showed the detergent treated fibre which have rougher surface. The rough fibre surface will improve the fibre to matrix adhesion hence reduce the possibility of fibre pull-out failure [9].

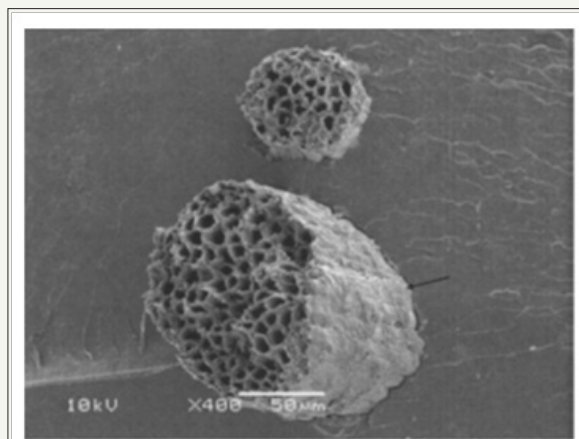

(a)

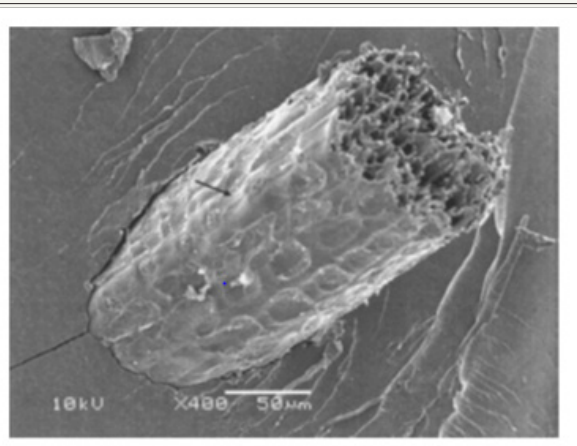

(b)

Figure 1: The SEM images of DPF/Polyester composite; (a) untreated fibre; (b) treated fibre [9].

The effect of using coupling agent and treatment on oil palm empty fruit bunch (opefb) and coir for polyester based bio composites have been reported by Hill \& Khalil [10]. They revealed that treating the both type of fibres could improve the tensile, flexural, and impact properties. However, the used of silane, and titanate coupling agents does not provide improvement on the opefb and coir composites. This is happened because of the using of coupling agent might induced strong fibre to matrix interfacial bond but it caused very efficient stress transfer that later reduce the toughness properties. As can be seen in Figure 2, the application of silane coupling agent also induce the matrix cracking around the fibre which has the potential cause of the lowered mechanical properties [10].
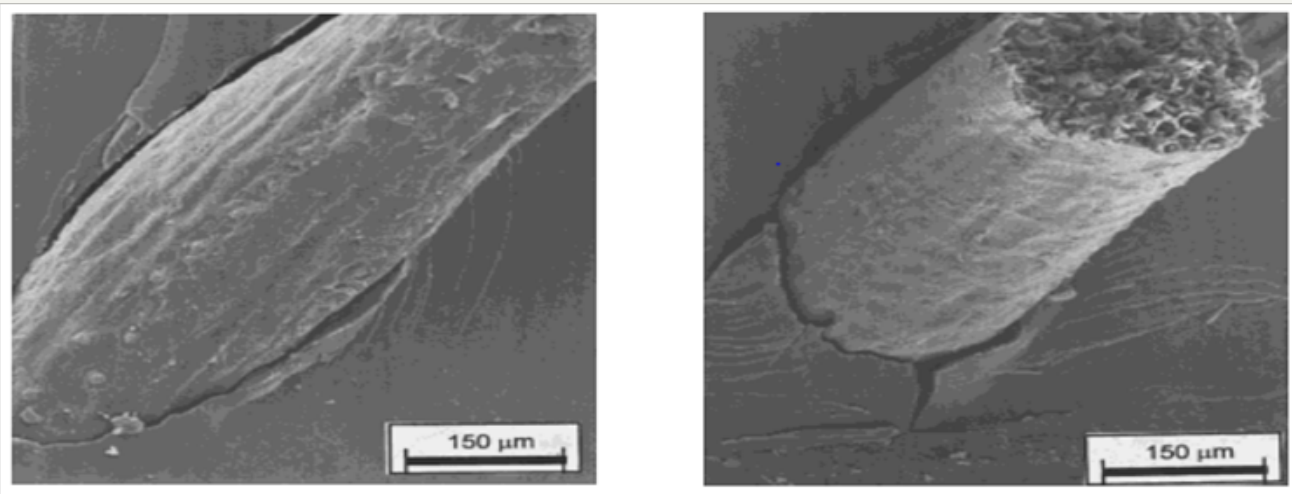

Figure 2: The comparison on SEM images of; (a) without additional coupling agent; (b) with silane coupling [10].

Epoxy resin: Another polymeric material in thermoset category is epoxy resin which created from multiple processing methods. Normally, epoxy is made from constituent chemical structure called oxirane or glycidyl group [11]. Apart from that, the petroleumbased epoxy monomers are known for superior properties such as tensile strength, high stiffness and excellent electrical strength. In addition, epoxy was widely applied in various applications in construction, automotive and aerospace industries owing to several desirable properties, such as e flame resistance, adhesive property, thermal property and chemical stability despites its good mechanical strength, dimensional stability, and good wetting ability [12].
Similar to polyester, epoxy also has received good attention for bio composite production as matrix resin. Oksman et al. [13] reported the production of sisal reinforced epoxy bio composite through RTM. The bio composite was produced from the variation of sisal fibre content from 30,37, and 48wt.\%. The addition of sisal fibre has successfully improved the tensile strength from $76 \mathrm{MPa}$ to $211 \mathrm{MPa}$ at $48 \mathrm{wt} . \%$ of fibre. Moreover, the tensile modulus also increased from $3.2 \mathrm{GPa}$ to $19.7 \mathrm{GPa}$ at same fibre content. However, the tensile strain dropped from $7.3 \%$ to $1.9 \%$ at same fibre content explaining the epoxy has become stiffer and lost its ductility characteristic. Despites the effectiveness of adding sisal fibre, SEM scanning has revealed the failure mechanism not only fibre pull- 
out but also fibre imprints during the fracture process as can be seen in Figure 3. This indicates weak fibre-matrix adhesion due to the different nature of hydrophilic (natural fibre) and hydrophobic (matrix resin) nature that created incompatibility issue.

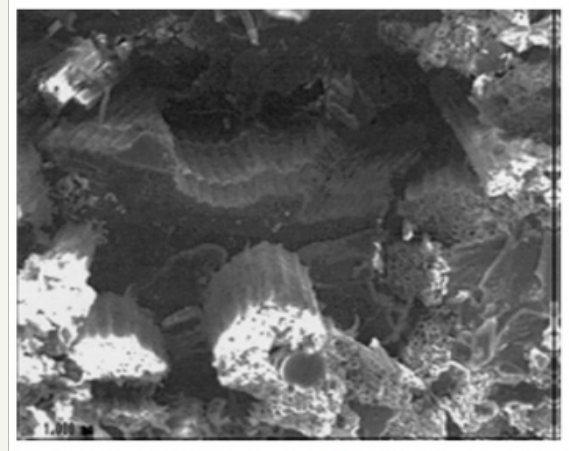

(a)

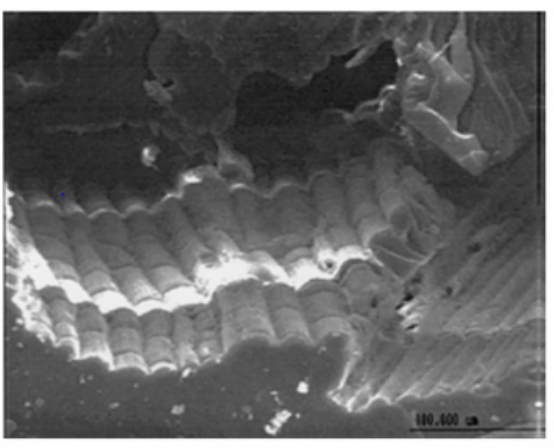

(b)

Figure 3: SEM image that revealed the failure mechanism on the tested sample; (a) fibre pull-out; (b) print of fibre surface [13].

Vinyl ester resin: Despites polyester and epoxy, vinyl ester is another thermoset plastic that is widely used for developing bio composite due to good stiffness and higher strength compared to polyester [14]. Other than that, the vinyl ester is easy to be handled at room temperature and have similar mechanical properties to epoxy. The using of vinyl ester for bio composite production will consume lower production cost since the vinyl ester is cheaper than epoxy [15]. Razali et al. [16] discovered the mechanical properties of roselle fibre reinforced vinyl ester bio composite. The roselle fibres were mixed uniformly with vinyl ester by using a mechanical stirrer at 100 to $250 \mathrm{rpm}$ with the variation on fibre content, 0,10 , $20,30,40 \mathrm{vol} . \%$. The tensile and impact tests showed the optimum fibre content at $20 \mathrm{vol} . \%$. The addition of roselle fibre at $20 \mathrm{vol} . \%$ increased the composite tensile strength from $18 \mathrm{MPa}$ to $42 \mathrm{MPa}$ and modulus from 1.8GPa to $2.5 \mathrm{GPa}$. This improvement justifies the effective and uniform stress distribution between the fibres to matrix at 20 vol.\%. In addition, this improvement also caused by good interfacial bonding between fibre to matrix, and uniform dispersion fibre in the matrix and the polymer.

In another study, Chen et al. [17] examined the chemical treatments on bamboo strip in order to modify its moisture absorption and adhesion towards vinyl ester resin. In their study, the composite was treated with four chemicals; sodium hydroxide, $\mathrm{NaOH}$ (alkali); sulphuric acid, $\mathrm{H}_{2} \mathrm{SO}_{4}$ (acetylation); potassium permanganate, $\mathrm{KMnO}_{4}$ (oxidization); and silane. Prior the bio composite production, the bamboo strips were immersed in four different chemicals and cleaned-dried after the immersion. Later, the bio composites with four different treated condition was placed in humidity chamber with three different relative humidity $(\mathrm{RH})$; $40 \%, 60 \%$, and $80 \%$. The results showed for interfacial shear strength (IFSS), there is improvement from the four types of chemical treatment, with the most significant can be found on the sample that treated with silane, $36.5 \%$ higher IFSS than untreated bamboo strips, followed by acetylation, permanganate, and alkaline treatments (by 25.5\%). The chemical treatment is successfully remove the smooth surface of bamboo strips that containing lignin, hemicellulose, and waxy layer hence rendered rougher surface, displayed in Figure 4. With this rougher surface, it will induce better mechanical interlocking between fibre and matrix. For the case the bio composite is subjected to moisture absorption, the increasing of RH level has reduced the IFSS of all four bio composites type, which the most significant dropping found at $80 \% \mathrm{RH}$. At this $\mathrm{RH}$ level, the silane treated bamboo strip produce the best IFSS compared to other chemicals treatment.

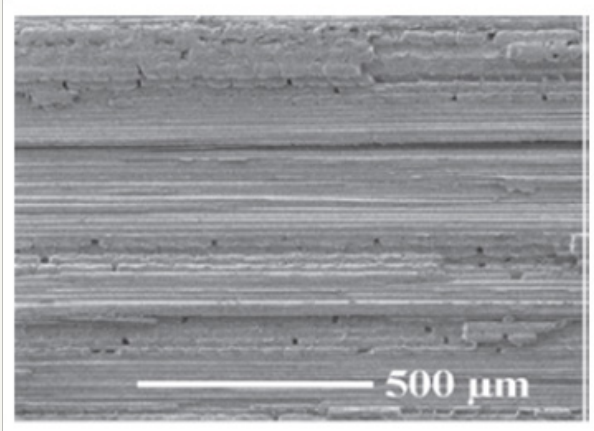

(a)

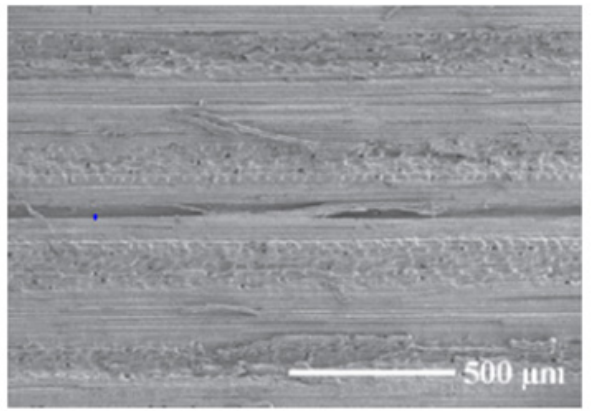

(b)

Figure 4: SEM image on the surface topology of the bamboo strip/vinyl ester; (a) untreated; (b) silane treated [17]. 


\section{Woven kenaf composite}

The woven kenaf fabric has received tremendous attention for bio composite production. This is because of the kenaf fibre has the economic and ecological advantages which is the plant could mature in 3 months, able to grow under a multiple range of weather conditions, able to achieve height more than $3 \mathrm{~m}$ with base diameter of $3-5 \mathrm{~cm}[18]$.

\section{Effect of fibre treatment}

In 2008, Lai et al. [19] revealed the flexural properties of woven kenaf reinforced polyester bio composite, along with the effect of fibre treatment. The fibre was treated by soaked in 6\% concentrations of $\mathrm{NaOH}$ solution for $3 \mathrm{~h}$ at room temperature.
Result of the treatment can be seen in Figure 5, which the soaking into alkali solution induced rougher fibre surface hence causing improvement in flexural properties. The effect of treatment improved $62 \%$ of flexural strength and $17 \%$ of flexural modulus, as compared to untreated fibre. The impurities such as hemicellulose, lignin, and waxes on the fibre surface have been dissolved in alkali solution thus introduce better mechanical interlocking and chemical bonding between the fibres to matrix. Other than that, the density of bio composite containing treated fibre also $4 \%$ higher than untreated one. This may contribute to the advancement on the flexural properties since the high density indicates more compact fibrils and improve packing of polymer chains leading to higher degree of crystallinity.

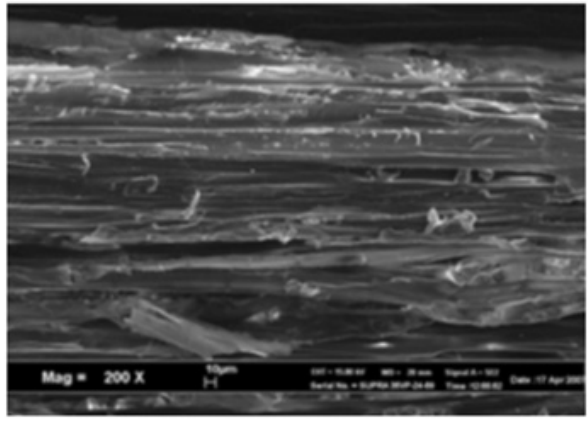

(a)

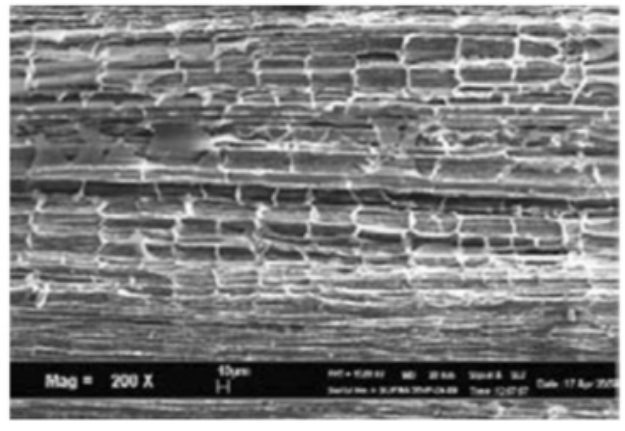

(b)

Figure 5: The comparison on kenaf fibre surface due to alkali treatment; (a) untreated fibre (b) treated fibre.

\section{Effect of weaving pattern}

Furthermore, the study on the effect of weaving pattern of woven kenaf reinforced polyester bio composite also reported by Alavudeen et al. [20] in order to find the best weaving that can provide excellent integrity and conformability. In their study, the plain and twill weaving pattern were used, as can be seen in Figure 6. Interestingly, the tensile strength of plain weave composite was $115 \mathrm{MPa}$ while twill weave composite was $65 \mathrm{MPa}$ which is almost $45 \%$ lower. In their opinion, this could be the plain weave causes the fibres interlaced one to one in both warp and weft direction contributing to uniform distribution of stress transfer from tensile load in both longitudinal and transverse directions, while there is no interlacing occur for twill weave fibre. Other than that, the treated kenaf woven with $10 \% \mathrm{NaOH}$ also exposed about $10 \%$ improvement on flexural strength as compared untreated woven kenaf. However, this flexural strength is $15 \%$ lowered than result obtained by Lai et al. [19], as the concentration of $\mathrm{NaOH}$ solution used by Alavudeen et al. [20] is higher than Lai et al. [19]. In addition, the failure on the woven fibre composite is reported due to complete removal of fibre bundles along the direction of loading, as shown in Figure 7.

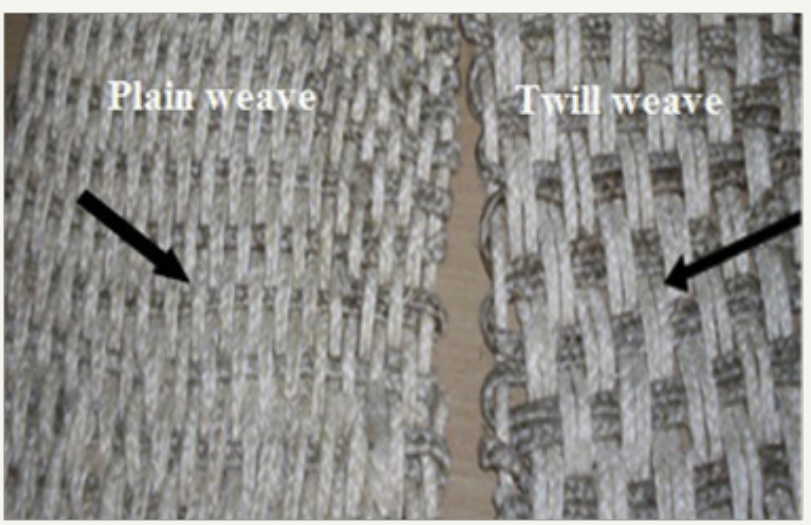

Figure 6: The weaving pattern used Alavudeen et al. [20]. 


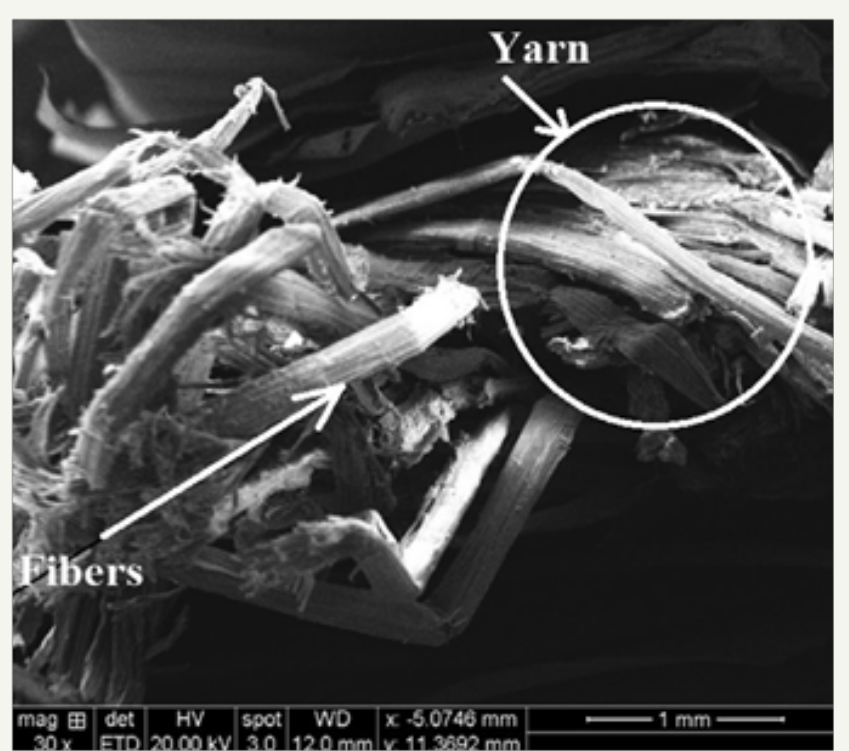

Figure 7: SEM image of woven composite indicating fibre removal.

\section{Effect of fibre hybridisation}

Despite on fibre treatment or varying weaving patter, the hybridisation of woven kenaf fibre with other fibre also can introduce better bio composite performance. This can be done by using two different types of fibre to reinforce a single matrix. The hybridization is later allow the manufacturer to obtain a balance of composite performance and cost hence thus catalyst the potential of hybrid fibre composites to be utilized in higher load structural applications ,for instance automotive component [21].

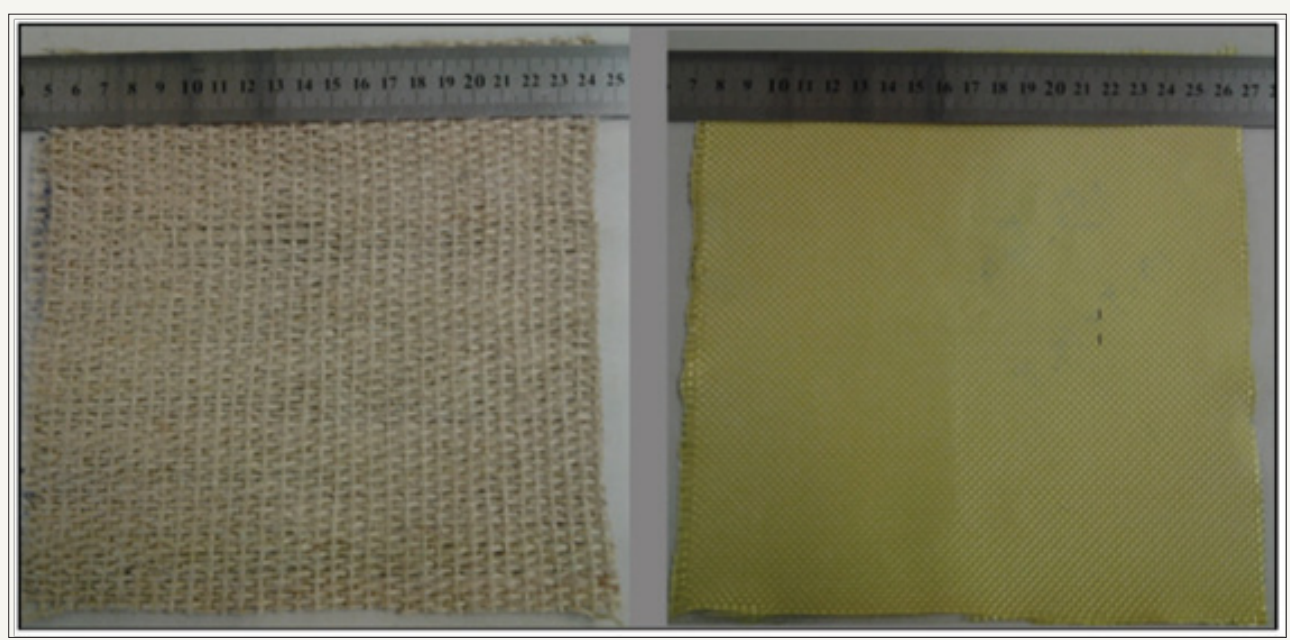

Figure 8: Woven kenaf and Kevlar used in this study.

Yahaya et al. [22] reported the hybrid woven kenaf/Kevlar reinforced epoxy bio composite was produced by varying the Kevlar to woven kenaf ratio as $78 / 22,63 / 47,50 / 50,26 / 74$, and $32 / 68$ wt.\% through hand layup method. Figure 8 showed the woven kenaf and woven Kevlar that used in this study. For the physical analysis, in high woven kenaf content, the density was found decreased while the void content was increased as well as the thickness of composite. These two conditions (increase in void content and thickness) were later reduced the tensile strength and modulus. Figure 9 proved the presence of voids indicating the fibre to matrix interface bond determined the tensile properties of hybrid composites. For the case of mechanical analysis, the increasing of void content was later reduced the tensile strength and modulus for higher woven kenaf content. The result showed the composite with $78 / 22$ wt.\% has the highest tensile strength and modulus (202MPa and 3.4GPa respectively), as compared to other hybrid samples since this sample contained a higher percentage of stronger and stiffer material. Meanwhile, the 63/47wt.\% composite was found has the highest flexural strength and modulus compared to other hybrid composites. For this reason, this may due to the effect of higher total fibre contents, void content, and fibre-matrix adhesion strength in the samples. It can be said, the Kevlar layers were put as outer and it absorbed more stress compared to woven kenaf. 


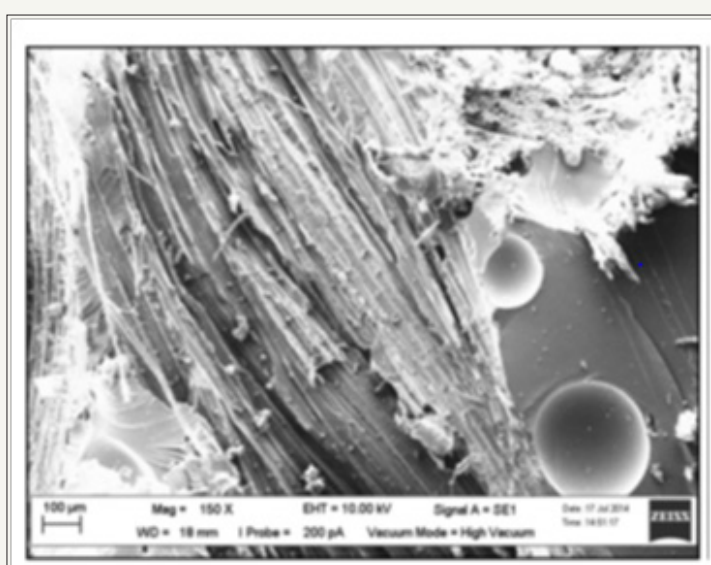

(a)

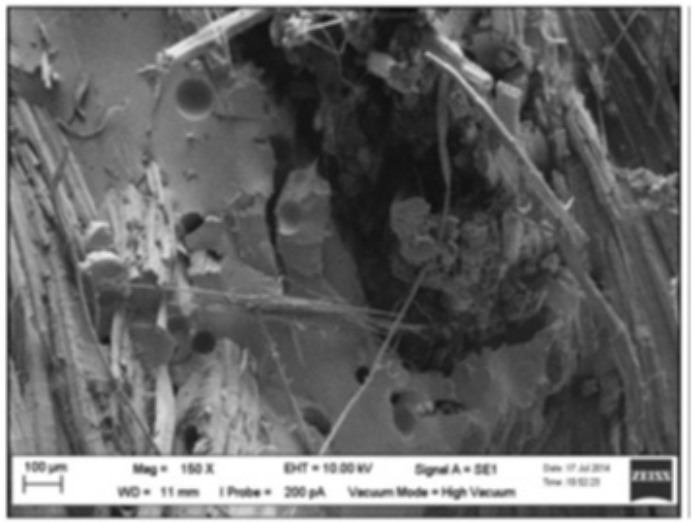

(b)

Figure 9: SEM images of fracture samples; (a) high Kevlar content (78/22 wt.\%); (b) high woven kenaf content (26/74 wt.\%).

\section{Conclusion}

The textile manufacturing has introduced the woven kenaf for engineering product development such as bio composite. With proper production process, the optimum material performance of bio composite could be obtained. This including fibre treatment with chemical, the use of coupling agent, and fibre content optimisation. In conclusion, the woven kenaf has showed good opportunity to be used for engineering purpose hence might increase its commercial value.

\section{References}

1. Holcombe BV (1983) Fire Safety J 6(1983):129.

2. Torvi DA (1996) Heat transfer in thin fibrous materials under high heat flux conditions. PhD Thesis, University of Alberta, Canada.

3. Kozlowski R, Przybylak MW (2001) Natural polymers, wood and lignocellulosic materials. Fire Retardant Materials. In: Horrocks AR, Price D (Eds.), Wood head Publishing Limited, Cambridge, England 2001.

4. Stull JO, Stull GG (2013) Evolution of moisture barrier use in PPE.

5. Stull JO, Stull GG (2013) Getting wet: Moisture effects on PPE performance.

6. Barker RL, Deaton AS, Ross KA (2011) Fire technology 47(3): 549.

7. Barker RL, Guerth-Schacher C, Grimes RV, Hamouda H (2006) Text Res J 76: 27.

8. Veghte JH (1987) Fire technolology 23(4): 313.

9. Stull JO (2000) Performance of protective clothing: Issues and Priorities for the 21st Century. In: Nelson CN, Henry NW, (Eds.), ASTM International, USA, p. 557.

10. Chakraborthy S, Kothari VK (2017) Effect of moisture and water on thermal protective performance of multilayered fabric assemblies for firefighters. Indian Journal of Fibres and Textile Research 42: 94-99.

11. Horrocks AR (2014) Polym Degrad Stabil 96: 377.
12. Levchik SV, Supresta LLC, Weil ED (2008) Developments in phosphorous flame retardants. Advances in Fire Retardant Materials. In: Horrocks AR, Price D, (Eds.), Wood head publishing, England.

13. Georlette P (2001) Applications of halogen flame retardants. Fire Retardant Materials. In: Horrocks AR, Price D, (Eds.), Wood head publishing, England.

14. Basak S, Samanta KK, Chattopadhyay SK, Das S, Narkar R, et al. (2013) Pol J Chem Technol 16: 106.

15. Hady AAE, Farouk A, Sharaf S (2013) Carbohydr Polym 92: 400

16. Kei SCH (2010) The effect of atmospheric pressure plasma on flame retardant property of cotton. Bachelor of Arts in Fashion Technology thesis, Institute of Textile and Clothing, Hong Kong Polytechnic University, China.

17. Joshi M, Ali SW, RajendranS (2007) J Appl Polym Sci 106:793.

18. Sarvanan D, Lakshmi SNS, Raja KS \& Vasahi NS (2013) Indian J Fibre Text Res 38: 156 .

19. Alongi J, Carletto RA, Balsio AD, Cuttica F, Carosio F, et al. (2013) Carbohydr Polym 96: 296.

20. Bosco F, Carletto RA, Alongi J, Marmo L, Blasio AD et al. (2012) Carbohydr Polym 94: 372.

21. Carosio F, Blasio AD, Cuttica F, Alongi J, Malucelli G (2014) Ind Eng Chem Res 53: 3917

22. Basak S, Samanta KK, Chattopadhyay SK, Narkar R, Mahangade R (2015) Int J Cloth Sci Technol 27: 247.

23. Basak S, Gupta D (2010) J Appl Polym Sci 117: 3448.

24. Basak S, Samanta KK, Chattopadhyay SK, Narkar R (2015) Cellulose 22: 2767.

25. Basak S, Patil P G, Shaikh A J \& Samanta KK (2016) J Chem Technol Biotechnol 91: 2871.

26. Basak S, Kartick K, Samanta KK, Chattopadhyay SK, Saxena S, et al. (2018) Banana pseudostem sap and boric acid-A new green intumescent for making self-extinguishing cotton fabric. Indian Journal of Fibres and Textile Research 43(1): 36. 
Creative Commons Attribution 4.0 International License

For possible submissions Click Here

Submit Article

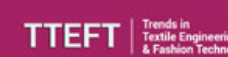

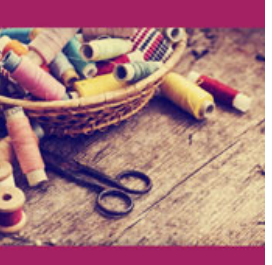

Trends in Textile Engineering \& Fashion Technology

\section{Benefits of Publishing with us}

- High-level peer review and editorial services

- Freely accessible online immediately upon publication

- Authors retain the copyright to their work

- Licensing it under a Creative Commons license

- Visibility through different online platforms 